\title{
A PLAN FOR ORAL TESTING IN THE LANGUAGE LABORATORY
}

\author{
by \\ Francis G. Jarlett
}

Here, in 4 steps is a simple procedure for administering oral tests in the language laboratory. Having used this method for a number of years, I would like to finally share it with other teachers in the hope of bringing an additional measure of order, direction, and, most of all, continuity both to language teaching and to the learning habits of our students. Here is how I go about working towards these goals.

Step 1. At the very beginning of the semester students will be thoroughly instructed in the operation of the language laboratory recorders. Inform them that after their training period they will have oral tests consisting of selected exercises from designated lessons, but that during the tests no texts or tape scripts will be allowed. Such exercises will all be taken from the lab material.

Note to step 1. Students need reassurance and abundant practice in listening and responding to taped exercises, as well as in operating the recorders before they take a formal test. Classes can and should be taken to the lab at frequent intervals so that they can familiarize themselves with their new routine. Some students are so apprehensive about performing on demand that they may beg to have a script with them for the test. In rare situations I have temporarily acquiesced by providing them with a sheet containing the barest indications of the nature of the drills. No harm is done; no principle is compromised. Students still realize that they must practice, for the test day inevitably comes and cannot be avoided.

Step 2. After finishing two or three textbook lessons in class, select 5 or 6 exercises from the laboratory taped material from those same lessons. Record these exercises from the master tape onto a blank tape. Copy five sentences from each exercise. You now have an examination tape containing $\mathbf{2 5}$ or $\mathbf{3 0}$ items. Such an examination will last $\mathbf{1 0}$ or, at the most, 15 minutes.

Note to step 2. Exercises to be selected should be self-explanatory to the ear, not to the eye. Therefore skip all visual signals such as fill-ins, infinitives in parentheses, etc. Avoid exercises whose responses do not indicate knowledge of grammar by the student, such as adjectives whose pronunciation is the same for masculine, feminine, singular or plural, or verb forms whose pronunciation does not indicate the person or number. Choose sentences whose responses are of a reasonable length. The teacher might test himself by putting himself in the student's place.

In preparing the examination tape, provided the master speed is $33 / 4$ ips, duplicate your excerpts onto your blank tape with both machines 
running at $71 / 2$ ips. The job is done quickly this way. With five sentences in each exercise, you have a convenient built-in locator. Since the correct responses of the master tape also appear on the student tape and provide sufficient information for the corrector, he can fast-forward past the often slow and repetitious instructions, saving considerable correcting time. At this point it is evident that I prefer using the exercises as they appear on the master tape. On the principle that what is good enough to be practiced is good enough to test.

Step 3. At the hour designated for the test, give each student a tape or cassette. The students record at their booths both the master and their own responses. When finished they check their tapes to make sure that they have made a recording and then they hand in their tapes to the teacher for correction.

Step 4. To grade the tapes the instructor plays them back on any recorder that picks up both tracks, usually the lab recorders. I have installed old or spare machines at convenient locations for teachers to use to correct tapes. The playback circuits on these machines usually function long after the recording circuits have outlived their usefulness.

My grading system is a simple adaptation of the honor point principle: an $A$ response equals $4, B$ is $3, C$ is $2, D$ is $1, F$ is $O$. 10 responses might have grades of $4,3,2,3,2,1,3,2,2,1$, totaling 23 , changed to 2.3 or a C. I have found students to be invariably receptive to this grading system once it is explained to them, because it is, I believe, honest, fair, neither too severe, nor too lenient. During the grading, the instructor might do well to bear in mind that grammatical accuracy is easily detected and measured. Not so pronunciation. An apparently sincere effort by the student to pronounce well should be acknowledged, but a response which betrays no intent to even remotely approximate a native pronunciation should be penalized. Remind students that this testing has cumulative rewards, that it adds a new technique to language acquisition, that it is not divorced from other aspects of language learning, and that it constantly exposes them to several native voices.

Note to Sept 4. The task of correcting the tapes can be made unnecessarily difficult and time-consuming if the teacher insists on listening to every syllable and notes every error of grammar or pronunciation. I feel that such zeal is a genuine waste of time. Detailed correction of student responses is most useful to the individual and to the class when pointed out and enlarged upon in the classroom. But should not be dwelt upon during the correction of tapes. That task is tedious and should not be prolonged. Students are genuinely grateful to the teacher who is interested in listening to their work; they do not demand an extravagant outlay of his time at dubious profit to them.

The above system of testing may seem uncomplicated and straightforward to many teachers. They may consider my explanations to be so 
detailed as to be patronizing. But those who are relatively inexperienced in the operation of language laboratory equipment may need instructions themselves before attempting to conduct such a test. The language laboratory director and others of similar expertise must guide their colleagues.

The testing I have just described has been peculiarly rewarding for me. I mention several personal rewards: the language laboratory becomes a truly active learning place where specific, concrete language-related techniques are practiced. Organized, disciplined work is performed and is suitably recognized, for the good students usually do well in oral performance, while the weaker ones do better in it than in written work, because, I suspect, oral performance is more physical, less intellectual, perhaps. Indeed exercises which many students, and teachers as well, find boring when studied on the printed page or lethargically mumbled over in the familiar, somnolent laboratory session suddenly become alive and command the students' attention when they appear as test material spoken by natives. Meanwhile back in the classroom there do exist teachers who are conspicuously American with an uncertain grasp of the foreign pronunciation they are teaching, or frequently there are native foreign teachers possessed of an unshakable regional accent. By contrast the voices on the tapes may strike the students as disciplined, well-trained, possibly interesting and even charming.

Certain administrative problems tend to disappear with this program. It is no longer necessary to require lab attendance or to be concerned with one hour a week or two hours a week versus class time. If we make the lab available, students will attend, because they must in order to prepare for their test. We in turn must provide them with taped material of reasonable length, short enough to practice in a session, with time for repeats. My candidates for long-windedness in this department are the 92 and the 108 minute ones. Both tapes were neatly boxed by the publisher, but with no indication that he had switched from $\mathbf{1 . 5}$ mil to 1.0 mil thickness. No, we must edit and condense tapes, using the best, rejecting the worst material.

In these years when dwindling enrollment in foreign languages is the rule, we would be startled to hear complaints that labs in high schools are too crowded to be properly scheduled. If such a problem exists, a partial and a sound solution is to duplicate any lessons students request on their own cassettes or open reels. High-speed cassette-to-cassette duplicators cost no more than 3 open-reel tape recorders or one IBM electric typewriter for the superintendent's secretary. Even without this duplicator a student could still record on his own tape from the console any lesson and then have it for his own use during any subsequent lab session.

There are many other tricks and techniques for making this entire procedure a smooth, orderly and relaxed experience. If my plan is old-hat, I beg the reade's indulgence. If I have converted others, it is a 
good omen for the future of foreign language study. I have often wished that someone else would do my work for me. I do the training of students, the editing of tapes, the selection of materials, the administering and the correction of all tests, oral and written, besides the preparation

of the tests. I cannot conceive of divorcing the laboratory learning experience from the customary classroom routine. Indeed it is because I work in both places that I can know, or make a sincere effort to know, what is suitable for oral work and what should be written. Only by training students personally can one gauge their reactions. Only by listening to their responses to laboratory material can one judge what is workable and what is not. Finally and indispensably, only through these experiences is the teacher truly prepared to compose his own materials when necessary and then, later, devise the increasingly creative materials for use in advanced language classes.

Convinced as I am of the soundness of my methods, I fail utterly to convert others. It is evidently an accepted practice to have technicians, assistants, monitors, whatever, do the classroom teacher's lab work: in "Successful Language Laboratory Performance" by Gary Eugene Scavnicky, (NALLD, Winter, 1976), this is unquestioned. I wonder if the innovators of the last twently or so years in our field would have been so strident in their "innovative" claims if they had immersed themselves beforehand in the petty problems of the language laboratory.

Massachusetts Istitute of Technology

Foreign Languages and Literatures Section

Cambridge, MA 02139

July, 1979: Director of the Language Lab. Coordination of all aspects of the language laboratory. Responsibilities include supervision of a technical assistant and student assistants; budget; lialson with the faculty; identification of new audio materials for classroom use; maintenance and cataloging of the tape library. Language teaching experience preferred in one or mor of the following areas--EFL, French, German, Russian or Spanish; opportunity to teach one course. Salary and rank commensurate with experience. Application deadline December 8, 1978. Equal Opportunity/Affirmative Action Employer. Prof. Margery Resnick, Director. 10/30/78 